\title{
FINNISH POLICIES AND PRACTICES FOR SUPPORTING DIFFERENT LEARNERS
}

\author{
AUTHORS' DATA: \\ Tuomo Vilpolla, $\mathrm{PhD}$ in Education \\ Faculty of Education, University of Oulu, Finland \\ University lecturer, Expert in inclusive education \\ Contacts: tuomo.vilppola@oulu.fi
}

Marianna Harutyunyan, $\mathrm{PhD}$ in Education, Associated professor

Chair of Speech and Rehabilitative Therapy, Khachatur Abovyan Armenian State University, Armenia

University Lecturer

Contacts: marianna.harutyunyan@aspu.am

\begin{abstract}
Nowadays the inclusive practices allow all pupils to attend the school they would attend if they did not have a disability, and no pupil can be deprived of placement, because of a disability unless they are a danger to themselves or other students. Pupils with special educational needs are included in the school population and served in the general education classes alongside students without disabilities. Unlike traditional education practices, inclusive education strives to provide intervention, remediation, and support within the general education classroom. Inclusive education is based on the principle according to which education should be delivered at different levels using multiple methods to meet the needs of all pupils. Anyway, some authors discuss the risk of inclusion, which only involves moving special education practices into the mainstream classes. From this perspective, inclusion comes to mean nothing more than integrating children with special educational needs into regular classrooms and the process of ordinary teaching leaves unchanged. Based on this it is very important to investigate and analyze "the inclusive education" provided in the schools from the teachers' points of view in order to find out the real picture about the inclusiveness from a very broad perspective.
\end{abstract}


From this perspective, the review of Finish policies and practices shows that inclusion itself and by its nature is the favored approach to education for pupils with special educational needs, whenever possible.

Key words: inclusion, inclusive education, children with special educational needs, Finnish policy of inclusive education, mainstreaming, segregation.

\section{INTRODUCTION}

Inclusion includes every individual's right to be treated equally, and to be accorded the same services and opportunities as everyone else. In a school setting, full inclusion involves educating all children in regular classrooms all of the time, regardless of the degree or severity of a disability. Effective inclusion programs take place in conjunction with a planned system of training and supports. Such programs usually involve the collaboration of a multidisciplinary team, which includes regular and special educators (or other personnel) as well as family members and peers (Inclusion and Parent Advocacy: A Resource Guide Disability Resources, 1996). Although there has been a recent push for schools to educate pupils with disabilities in the general education classroom; however, in past years, the integration of pupils with disabilities with their typically developing peers was known as mainstreaming, which is different from inclusion in several ways. Mainstreaming is typically limited to putting a person with a disability next to typical people in the usually quite vague and unspecific hope that each will adapt to and learn about the other (Ainscow, Booth, \& Dyson, 2006; Dyson, Farell, Polat \& Hutchenson, 2004). This refers to the practice of educating students with special educational needs in classes with non-disabled students during specific time periods based on their skills. Students with special needs are segregated in separate classes exclusively for students with special needs for the rest of the school day (Zittleman \& Sadker, 2006). Segregation in a separate classroom or special school exclusively for students with special educational needs is seen when students with special educational needs spend no time in classes with non-disabled students. Segregated students may attend the same school where regular classes are provided, but spend all instructional time exclusively in a separate classroom for students with special needs (Febo, 2016). In the case when the special class is located in a mainstream school, children with special educational needs may be provided with the opportunities 
for social interaction, integration outside of their classroom, for example in canteen, playground etc. (Hicks, 2011).

A policy of inclusion is generally understood around the world as part of a human rights agenda that demands access to, and equity in, education (Florian, 2008, p.202). Approaches to schooling of students with disabilities and other special needs have occurred interactively with civil and human rights movements. The move is always from segregated models of learning and towards schools designed to educate all children together (Peterson \& Hittie, 2003).

The recent tendency in Europe is also to develop a policy towards the inclusion of students with special educational needs into mainstream schools, providing teachers with varying degrees of support in terms of supplementary staff, materials, in-service training, and equipment (European Agency for Development in Special Needs Education, 2003).

In many ways the Finnish school system is inclusive by nature (UNESCO, 2007). Development towards the school for everyone has begun years ago. Legislation that directs the Finnish education system is based on equality, justice of learning and on the principle of inclusion. The most important goal of education is to support growth and development of unique personality in all possible ways (UNESCO, 2007).

Finland's exceptional education system has long been a role model for the international community (OECD, 2014a; OECD, 2014b; OECD, 2014c; OECD, 2013).

\section{LITERATURE REVIEW}

The movement to integrate special education students into normal school classes started to develop in Finland in the 1960s (Moberg \& Zumberg , 1994) and today in many ways the Finnish school system is inclusive by nature (Jarvinen, 2007). As it was already mentioned, the most important goal of education in Finland is supporting growth and development of unique personality in all possible ways. Schooling is provided first and foremost in context with mainstream education (UNESCO, 2007). Also the main goal of education is to guarantee the best possible learning to everyone. Every child is important and all the decisions are made from the children point of view (UNESCO, 2007; Jarvinen, 2007).

Nowadays the Finnish Parliament decides on educational legislation and the general principles of education policy and the government, the Ministry of Education, and the Finnish National Board of Education are responsible for the implementation of this policy at the central 
administration level (UNESCO, 2007). The government participates in the costs of schools by paying the so-called statutory government transfer to the education provider. The role of the Ministry is to prepare strategic policy guidelines for education, to prepare and share budget and to prepare educational laws. The main responsibility of NBE is to prepare and decide about the National Core Curriculum for schools and development of the Finnish education system (UNESCO, 2007; Jarvinen, 2007).

In history the dialogue on inclusion in Finland has commonly focused on pragmatic issues, especially on what comprises the best learning environment for learners with various learning needs, and on the consequences of integrating a learner with a disability into a mainstream classroom (Engelbrecht, Savolainen, Nel \& Malinen, 2013). Due to this emphasis, the commitment to inclusion in Finland has traditionally tended to focus on the unique organizational traits and right actions mainstream schools require to provide support for learners with special education needs, preferably in separate settings in mainstream schools. Teacher education for inclusion has, consequently, focused on a separate program for those who intend to provide support for learners with special education needs in mainstream schools. As a result, comprehensive schools in Finland have retained some aspects of differentiation despite the fact that the reform adopted in the 1970s aimed to increase sociocultural, geographical and gender equity (Savolainen, Engelbrecht, Nal \& Malinen, 2012). Special education support in mainstream schools has continued to grow, and largely relies on a pull-out as well as separate classroom models of instruction and support, based on a deficit approach to learners with disabilities and other special educational needs. In order to develop a more inclusive approach within mainstream classrooms, there has been systematic reform in recent years to move Finnish schools away from separate special needs programs within mainstream schools towards a more inclusive direction through a new Special Education Strategy (Finnish Ministry of Education 2007 - www.minedu.fi), the Revised Act on Basic Education (Finnish Law 642/2010 - www.finlex.fi) and the updated National Curriculum Guidelines (Finnish National Board of Education 2010 - www.oph.fi). Based on to the Revised Act on Basic Education, schools are now required to show evidence of adequate learning support in mainstream classrooms before any learner can be given more intensive separate learning support, and the decision about a learner's needs are now principally based on a review by the teacher. These recommendations have been seen as radical in some circles, and the Trade Union of Education in Finland has expressed their concern that teachers' workload will increase, and that they do not have sufficient 
professional skills related to disabilities, mainly because traditionally specially trained special education teachers have been responsible for the support of learners with special educational needs (Malinen, Vaisanen, \& Savolainen, 2012).

Education for all in one school is the leading principle nowadays in Finland (Takala, Haussttatter, Ahl, \& Head, 2012). And there is an individualized understanding of special education with a strong focus on different kinds of learning problems, methodological solutions and individual development and evaluations in Finnish educational system. Here the provision of special education, including segregated provision, is seen as part of inclusive education, especially the so-called part-time special education which does not demand an individual educational plan developed for children with special educational needs (Takala, Pirttimaa, \& Törmänen 2009).

After getting acquainted more convincingly with the theoretical background of inclusive education in Finland we will shift to practical experience that every reader will find fascinating and worthy to know. Visiting a Finnish school leaves you amazed at first. It is a habit to swop your shoes for a pair of cozy slippers when entering the building, the children feel like they are at home and relaxed. All students call their teachers by their first names and no any tense and formal relationship exists. Above all the concept of including students with learning difficulties is deeply embedded in the system. Academically strong and weak students, as well as students with disabilities, are actually being taught in the same classroom (http://www.educationworldwide.de/Education-in-Finland-7023_e.html). It means putting in place a whole suite of provisions, including individualized curriculum, individualized teaching methods, modified assessment techniques and accessibility arrangements, all of which require support for the educator at the classroom level (Mitchell, 2008).

\section{POLICY PUSHES}

Amendments to the National Core Curricula for pre-primary and basic education happened in Finland in 2016. It reflects to organization of the support in inclusive schools. The main point of this is the possible earliest support in order to prevent the development and progression of the existing problems. Basic education is the same for all (European Agency for Special Needs and Inclusive Education,2020). There is no streaming, but children are supported individually so that they can

successfully complete their basic education (European Agency for Special Needs and Inclusive Education,2020; Finnish National Board of Education, 2016). Based on this education providers, 
municipalities and private education providers, draw up local curricula and annual plans on the basis of the national core curriculum. The local curricula complement the objectives, core contents and other aspects related to instruction with local emphases. The needs of the pupils, local specificities as well as results from self-evaluation and development work are taken into account (Finnish National Board of Education, 2016). The essential aims of the new curriculum, are to develop the school culture and to promote instruction with an integrative approach. The aim is that all pupils, despite the fact or having or not special educational needs, will:

- understand the relationship and interdependencies between different learning contents;

- be able to combine the knowledge and skills provided by different subjects to form meaningful wholes;

- be able to adopt and use these in collaborative learning (Finnish National Board of Education, 2016).

According to PORI (Special education in Finland and Myötätuulen koulu) the support for growth, learning and school attendance is shaped into three main categories in Finland which is presented in table 1:

Table 1.

Three main categories of support students in school.

\begin{tabular}{|l|l|}
\hline General support & Everyone has rights to general support. \\
\hline \multicolumn{2}{|c|}{ Intensified and special supports are based on careful assessment and long-span planning i } \\
multi-professional teams and on individual learning plans for pupils.
\end{tabular}




\begin{tabular}{|l|l|}
\hline Based on this information, the education provider makes an official \\
decision concerning special support (EACEA National Policies \\
Platform, Eurydice, 2019). Based on the subsequent decision, an \\
individual learning plan is required to be developed.
\end{tabular}

\section{PRACTICAL IMPLICATIONS}

To guarantee the success of learning, teachers seek to give pupils personal goals and learning methods. In school practice, while working with children with different abilities it means:

- Individualized curriculum

- Individualized assessment

- Individualized teaching

- Acceptance

- Access, and

- Support.

Let's reflect too each of these concepts shortly.

Individualized curriculum - making modifications to the curriculum is central to inclusive education; probably the biggest challenge educators face in creating inclusive classroom settings. It is a single curriculum that is, as far as possibly, accessible to all learners, including those with special needs. It includes activities that are age-appropriate, but are pitched at a developmentally appropriate level (Mitchell, 2015). To make the curriculum accessible, consider modification, substitution, omission and compensation in relation to content, teaching materials, and the responses expected from the learners.

Individualized assessment - when assessment is used for selection or ranking it is inevitable that learners with special education needs will fare the worst, thus stigmatizing them as failures and de-motivating them. It should assist you to adapt the curriculum and your teaching methods to all learners. So it allows you to diagnose why something occurred and then re-design learning opportunities. It should provide feedback to learners and parents. It should have focused on identifying what has not been achieved in rather than putting learners in some kind of order of merit. The adapted assessment should take account of leaners 'particular needs of support. Assessment 
should result in individual learning plan. An Individual learning plan does not require a learner be given individual teaching. Rather that means a larger awareness of individual needs.

Individualized teaching - teachers should have a wide repertoire of pedagogical and professional skills. Their focus should be managing learning rather than managing learner's behavior. Teachers require learners to complete their tasks and same time create positive self-beliefs in their students. Teachers always reflect their teaching and classroom outcomes. They fully consider learner's cultural and language backgrounds in planning and delivering teaching. They are authoritative not authoritarians! And humor is always present in teaching. Teachers themselves can choose the teaching methods they use in order to achieve the objectives stated in the curriculum and pupils' individual education plans. The national core curriculum includes the guidelines for choosing the methods. In addition to the traditional and still common method led by the teacher, there are more and more teaching methods that focus on pupils.

Acceptance - inclusive education relies on educators, learners and their parents and all the society accepting the right of learners with special educational needs to be educated in general education classrooms and receive equitable resourcing (Mitchell, 2015).

Access - Physical environment: For learners with physical disabilities to be included, adequate access to classroom must be provided. This can mean ramps, lifts, adapted toilets, wide doorways, adequate space for wheelchairs in the classroom. Mental ethos/atmosphere: The joint values of teachers behind teaching practices (e.g. understanding of inclusion, ethics of care) sense of belonging and being heard is essential. Social interaction: Principal of equality, preventing bullying, meaning of teacher-student relationships, importance of peer group (teaming up a teaching group).

Support - usually inclusive schools are served by multiple-skill student health care teams. The teams can include the principal, a school nurse and school doctor, a school social worker, a school psychologist, a special needs teacher and guidance counselor. The student welfare team works to promote the wellbeing of the school community and seeks solutions to assist pupils in need for support (Family Support, Helsinki, 2018). A pupil could have multi-professional support: assistant teachers, occupational, speech or physic therapists, psychologists, learning assistants. Teacher in inclusive setting should have good teamwork and leadership skills.

While reflecting to practical implication of existing policies in Finland it is very important to pay special attention on resources. Obviously inclusive education requires high levels of resourcing. 
At the same time, the inclusive education might be more economically viable, given the expense involved in transporting and accommodating learners in special school, especially in rural areas.

To bring all of the before mentioned elements together, leadership is required at all levels: government, national education departments and ministries, district departments, school principals and classroom teachers. Within this scope Finnish educational system gives an opportunity to all parties concerned to be flexible and create all possible placements for children with different needs in mainstream school. Placement here is understood as an age-appropriate classroom in the learner's neighborhood school despite the fact of child's educational needs. It is important that learners with special educational needs are not then placed in ability-based groups for all their activities.

\section{CONCLUSION}

Conducted literature review regarding policy and practice in Finish school to support all learners we can state that Finnish school culture makes concrete values. Finnish functions as a learning community that takes care of the safety and wellbeing of each and every member of the community, systematically promotes versatile working approaches as well as cooperation and interaction. Thus Finnish school promotes equity and equality in practice and takes responsibility for the environment and focuses on a maintainable future.

Special attention is paid to the fact that mainstream schools offer opportunities for individual and shared learning for all its members (Finnish National Board of Education, 2016). All members take each other into account through a dialogic interaction, striving to adapt their own actions to the activities of each learner and the whole school community.

\section{REFERENCE LIST}

1. Ainscow, M., Booth, T., \& Dyson, A. (2006). Improving schools, developing inclusion. Abingdon: Routledge.

2. Dyson, D.A., Farell, P., Polat, F., \& Hutchenson, G. (2004). Inclusion and pupil achievement. Research Report No. RR578. London: DfES.

3. Engelbrecht, P., Savolainen, H., Nel, M., \& Malinen, O. (2013) How cultural histories shape South African and Finnish teachers' attitudes towards inclusive education: a comparative analysis, European Journal of Special Needs Education, 28:3, 305-318. 
4. Family Support, Helsinki (2018). https://www.hel.fi/sote/perheentuki-en/school-agedchildren/student-welfare.

5. Febo, I., M. (2016). "Extended Learning Time". Seton Hall University Dissertations and Theses (ETDs). 2196. https://scholarship.shu.edu/dissertations/2196.

6. FINLAND, Regional Preparatory Workshop on Inclusive Education Eastern and South Eastern Europe Sinaia, Romania, 14 - 16 June 2007, UNESCO.

7. Finnish Law 642/2010, www.finlex. fi

8. Finnish Ministry of Education 2007, www.minedu.fi

9. Finnish National Board of Education 2010, www.oph.fi

10. Finnish National Board of Education (2016). New national core curriculum for basic education: focus on school culture and integrative approach, https://www.oph.fi/sites/default/files/documents/new-national-core-curriculum-for-basiceducation.pdf

11. Florian, L. (2008). Special or inclusive education: future trends. British Journal of Special Education. Vol 35. Number 4.

12. Hicks, B. (2011). "Disabled children excluded from education". BBC Online. Retrieved 13 June 2012.

13. Inclusion and Parent Advocacy: A Resource Guide (c) 1996, Disability Resources, inc.

14. Jarvinen, R. (2007). Current trends in inclusive education in Finland. FNBE, Preschool and Basic Education Development, UNESCO, IBE/Romania.

15. Malinen, O., P., Vaisanen, \& Savolainen, H. (2012) Teacher Education in Finland: Rowing against the Global Currents of Preparing Teachers for the Future. Joensuu: University of Eastern Finland. /unpublished manuscript/.

16. Mitchell, D. (2015). Inclusive Education is a Multi-Faceted Concept, CEPS Journal, Vol.5 (1)

17. Mitchell, D. (2008). What really works in inclusive education. Using evidence-based teaching strategies. London and New York. Routledge.

18. Moberg S, \& Zumberg M, (1994). Inclusive education in Finland: present and future perspectives. Psychol Rep. Dec;75(3 Pt 2):1519-22

19. Peterson, M.J., \& Hittie, M. M. (2003). Inclusive teaching. Creating Effective Schools for All Learners. A and B. Printed in United States of America. 
20. OECD (2014a), PISA 2012 Results: What Students Know and Can Do - Student Performance in Mathematics, Reading and Science (Volume I, Revised edition, February 2014), PISA, OECD Publishing, Paris. http://dx.doi.org/10.1787/9789264208780-en

21. OECD (2014b), PISA 2012 Results: Creative Problem Solving (Volume V): Students' Skills in Tackling Real-Life Problems, PISA, OECD Publishing, Paris. http://dx.doi.org/10.1787/9789264208070-en

22. OECD (2014c), PISA 2012 Results: Students and Money (Volume VI): Financial Literacy Skills for the 21st Century, PISA, OECD Publishing, Paris. http://dx.doi.org/10.1787/9789264208094-en

23. OECD (2013), PISA 2012 Assessment and Analytical Framework: Mathematics, Reading, Science, Problem Solving and Financial Literacy, PISA, OECD Publishing, Paris. http://dx.doi.org/10.1787/9789264190511-en

24. Savolainen, H., Engelbrecht. P., Nel M., \& Malinen. O. (2012) "Understanding Teachers'Attitudes and Self-Efficacy in Inclusive Education: Implications for Pre-Service and In-Service Teacher Education.” European Journal of Special Needs Education 27: 5168.

25. Special Education across Europe in 2003 Trends in provision in 18 European countries, European Agency for Development in Special Needs Education, 2003

26. Special Education Needs Provision within Mainstream Education, Finland, European Commission, EACEA National Policies Platform, Eurydice https://eacea.ec.europa.eu/national-policies/eurydice/finland/special-education-needsprovision-within-mainstream-education_en

27. Support for learning and schoolgoing, City of Helsinki https://www.hel.fi/helsinki/en/childhood-and-education/comprehensive/studentassistance/tehostettu-erityinen-tuki

28. Takala, M., Haussttätter, R. S., Ahl, A. \& Head, G. (2012) Inclusion seen by student teachers in special education: differences among Finnish, Norwegian and Swedish students, European Journal of Teacher Education, 35:3, 305-325.

29. Takala, M., Pirttimaa, R., \& Törmänen, M. (2009). Inclusive special education: the role of special education teachers in Finland. British Journal of Special Education. Volume 36. Number 3. 2009. 
30. Zittleman, K., \& Sadker, D. M. (2006). Teachers, schools and society: A brief introduction to education with bind-in online learning center card with free student reader CD-ROM. McGraw-Hill Humanities/Social Sciences/Languages.

31. http://www.education-worldwide.de/Education-in-Finland-7023_e.html

32. https://peda.net/pori/perusopetus/koulujen-kotisivut/erityiskoulut/herttuankoulu/inenglish/iel 